\title{
Husserl e Gurwitsch sobre a Psicologia da Gestalt: um Estudo sobre o
}

\author{
"Sensualismo" \\ Hernani Pereira dos Santos* \\ Pontifícia Universidade Católica do Paraná - PUC-PR, Londrina, PR, Brasil \\ ORCID: https://orcid.org/0000-0001-5003-4143
}

\section{RESUMO}

Este estudo aproxima fenomenologia e Psicologia da Gestalt tendo por eixo o tema do sensualismo na teoria da percepção. Propõe-se analisar a maneira como a Psicologia da Gestalt é avaliada dentro do sistema das investigações fenomenológicas de Husserl e de Gurwitsch. Começa-se por uma breve análise da problemática, confrontando os argumentos de Husserl e de Gurwitsch. Na segunda seção, propõe-se uma análise da teoria da percepção desenvolvida por Husserl em Ideias I. Mostra-se como o conceito de hylē desempenha aí um papel central. Na terceira seção, analisam-se as inovações da fenomenologia desenvolvida por Gurwitsch a partir da interpretação proposta pelo autor a respeito da Psicologia da Gestalt. Mostra-se como, para Gurwitsch, esta teoria psicológica renova a compreensão fenomenológica da organização perceptiva e, por isto, descarta uma determinada interpretação do conceito de hylē com base em um novo conceito de intencionalidade. Ao final, algumas conclusões para as duas linhas argumentativas são propostas.

Palavras-chave: epistemologia, fenomenologia, intencionalidade, percepção de forma e contorno, psicologia da Gestalt.

\section{Husserl and Gurwitsch on Gestalt Psychology: a Study about "Sensualism"}

\begin{abstract}
In this study, phenomenology and Gestalt psychology are approached as from the subject of sensualism in the theory of perception. It is proposed an analysis of how Gestalt Psychology is evaluated within the phenomenological research system of Husserl and of Gurwitsch. It begins with a brief analysis of the problem, confronting the arguments of Husserl and Gurwitsch. In the second section, an analysis of the theory of perception developed by Husserl in Ideas I is proposed. It is shown how the concept of hyle plays there a central role. In the third section, the innovations in phenomenology developed by Gurwitsch taking on base his interpretation of Gestalt psychology are analyzed. It is shown how, for Gurwitsch, this psychological theory renews the phenomenological understanding of perceptual organization and, therefore, discards a certain interpretation of the concept of hyle based on a new concept of intentionality. In the final section, some conclusions are proposed for the two lines of argument studied.
\end{abstract}


Keywords: epistemology, form and shape perception, Gestalt Psychology, intentionality, phenomenology

\title{
Husserl y Gurwitsch acerca de la Psicología de la Gestalt: un Estudio sobre
}

\author{
el "Sensualismo"
}

\begin{abstract}
RESUMEN
Este estudio acerca la fenomenología y la psicología de la Gestalt desde el tema del sensualismo en la teoría de la percepción. Se propone analizar la forma en que se evalúa la Psicología de la Gestalt dentro del sistema de investigaciones fenomenológicas de Husserl y Gurwitsch. Comienza con un breve análisis del problema, confrontando los argumentos de Husserl y Gurwitsch. En la segunda sección, se propone un análisis de la teoría de la percepción desarrollada por Husserl en Ideas I. Muestra cómo el concepto de hylē desempeña un papel central allí. En la tercera sección, las innovaciones en fenomenología desarrolladas por Gurwitsch se analizan con base en la interpretación que el autor propone con respecto a la psicología de la Gestalt. Se muestra cómo, para Gurwitsch, esta teoría psicológica renueva la comprensión fenomenológica de la organización perceptiva y, por lo tanto, descarta una cierta interpretación del concepto de hylē basada en un nuevo concepto de intencionalidad. Al final, se proponen algunas conclusiones para las dos líneas de argumento estudiadas.
\end{abstract}

Palabras clave: epistemología, fenomenología, intencionalidad, percepción de forma y contorno, psicología de la Gestalt.

Desde a tradição husserliana, a fenomenologia é entendida como ciência eidética dedicada ao estudo analítico e descritivo dos fenômenos originariamente dados à experiência e da estrutura que rege a manifestação destes fenômenos, considerando-se o ponto de vista do ato (noético) e o ponto de vista do objeto intencionado (ponto de vista noemático) como entrelaçados. Como filosofia transcendental, ela destaca a função epistêmica da experiência e centra-se sobre como é possível o conhecimento de objetos transcendentes na imanência. Dado isto, não é sem razão que um de seus principais temas de estudo seja a percepção. Conforme o que o autor afirma em "Ideias I": "A experiência doadora originária é a percepção, tomada no sentido habitual da palavra" (Husserl, 1913/1976, p. 8). Muitos dos estudos de Husserl e de outros fenomenólogos, de gerações distintas, como Aron Gurwitsch e Merleau-Ponty, para citar apenas alguns, foram dedicados ao tema da percepção.

Contudo, ao menos explicitamente, pouco papel é concedido por Husserl a um debate mais explícito de ideias com autores da psicologia de sua época (Peres, 2015). Ao abordar a 
Psicologia da Gestalt em um de seus textos tardios, Husserl (1931/1986) a classifica como "sensualismo", ao lado da psicologia descritiva de Brentano. As razões para esta abordagem sumária da Psicologia da Gestalt e para esta classificação taxativa ficam obscuras no texto em questão. Em uma resenha deste mesmo texto, publicada um ano mais tarde, Aron Gurwitsch (1932/2009b) lamentaria a pouca dedicação de Husserl ao embate com a Psicologia da Gestalt, o qual, acredita, teria enriquecido as suas descrições da percepção. Gurwitsch (1929/2009a; 1936/2009c; 1964/2010), ele mesmo, ter-se-ia dedicado, em várias ocasiões, a um exame aprofundado das teses desta escola de psicologia científica e de seu significado para as investigações fenomenológicas.

Neste estudo, pretende-se analisar a maneira como a Psicologia da Gestalt é avaliada dentro do sistema das investigações fenomenológicas de Husserl, em especial com relação à sua teoria da percepção, e confrontar esta avaliação com aquela contrária, feita por Gurwitsch. Não se pretende fazer uma análise exaustiva das relações entre fenomenologia e Psicologia da Gestalt, mas contribuir para a clarificação de teses básicas de uma teoria fenomenológica da percepção a partir de trabalhos de Husserl e de Gurwitsch. A ênfase está no conceito de "sensualismo". Dado isto, começa-se por uma breve análise da problemática, confrontando os argumentos do "Epílogo" de Husserl (1931/1986) com a resenha de Gurwitsch (1932/2009b). Na segunda seção, propõe-se uma análise da teoria da percepção desenvolvida em "Ideias I" (Husserl, 1913/1976) e que dá base para os argumentos de Husserl em seu "Epílogo". Mostrase como o conceito de hylē desempenha um papel central nesta teoria. Na terceira seção, analisam-se as inovações da fenomenologia desenvolvida por Gurwitsch (1929/2009a) em sua tese de doutoramento, "Fenomenologia da temática e do eu puro". Mostra-se como, para Gurwitsch, esta teoria psicológica renova a compreensão fenomenológica da organização perceptiva e, por isto, descarta uma determinada interpretação do conceito de hyle com base em um novo conceito de intencionalidade.

\section{Fenomenologia e Psicologia da Gestalt: um Encontro Possível?}

Por ocasião da publicação de "Ideias I" em inglês, Husserl escrevera o seu "Epílogo" de 1931 (Husserl, 1931/1986), onde apresentou, de maneira sintética e mais sistemática, o programa da fenomenologia transcendental e as suas ideias básicas. Ao apresentar a origem do conceito fenomenológico de intencionalidade e confrontar a fenomenologia transcendental com a psicologia, Husserl dedicou, ali, um breve comentário à psicologia empírica de sua época, onde se incluem a psicologia descritiva de Brentano e, também, a Psicologia da 
Gestalt. Neste contexto, Husserl afirma uma diferença radical entre o programa da fenomenologia transcendental e toda a psicologia moderna. Com base em sua teoria da constituição, ele defende uma posição não-naturalista para a fenomenologia transcendental e a opõe ao naturalismo e ao sensualismo de toda a psicologia moderna. Estas duas oposições são importantes para compreender a sua teoria da percepção e da consciência.

Para Husserl, o naturalismo corresponde a uma forma de conhecer e fixar conceitualmente os fenômenos da experiência. Em seus termos, fala-se não do naturalismo como um sistema filosófico, mas como uma atitude, a saber, a "atitude naturalística", mais bem tematizada e analisada em seus textos tardios (Husserl, 2012). Conforme Ramstead (2015), é possível distinguir, nas diversas posições que Husserl assume ao longo de sua obra, três formas básicas de naturalismo: (a) o naturalismo metodológico; (b) o naturalismo epistemológico; (c) e o naturalismo ontológico. E a cada forma de naturalismo corresponde uma variante forte e uma variante fraca (Ramstead, 2015). Sem nos determos nos pormenores desta distinção, cabe salientar que, para Husserl, o compromisso tanto com o naturalismo epistemológico quanto com o naturalismo ontológico, em suas variantes fortes e fracas, é insustentável por acarretar um negligenciamento, qual seja: (1) da função epistêmica da consciência, irredutível a uma coisa psicológica (forma ontológica), e (2) do problema da justificação do conhecimento e da possibilidade de um conhecimento não-empírico, como a lógica e a aritmética (forma epistemológica).

No interior desta questão, o sensualismo ganha o seu sentido como um impasse na análise da função epistêmica da consciência, não permitindo dar conta inteiramente da problemática da justificação do conhecimento e da possibilidade de um conhecimento nãoempírico, como a lógica e a própria filosofia. Coloca-se como uma resposta ao problema do conhecimento que não alcança mais do que o registro dos eventos psíquicos e não permite, por isso, alcançar nem o estatuto próprio (chamado por Husserl de "eidético") dos enunciados lógicos (Husserl, 1984) nem o seu estatuto propriamente transcendental (Husserl, 1913/1976). Sendo assim, o sensualismo não é diferente do psicologismo cujos impasses são apontados no primeiro volume das "Investigações Lógicas" (doravante, IL) (Husserl, 1984). E é neste registro que Husserl localiza a Psicologia da Gestalt. O seu embate com ela é, portanto, epistemológico - deixa-se entre parênteses a validade de suas teses enquanto interpretações ou explicações dos fatos psicológicos.

Ora, considerado de um ponto de vista genealógico, o programa da "teoria da Gestalt" (Gestalttheorie) se origina a partir do quadro lógico que é a psicologia empírica, de maneira que engloba especificidades da psicologia descritiva e, também, problemas genéticos-causais. 
Ela herda o aspecto metodológico da psicologia de Brentano, sobretudo a sua preocupação em ater-se à percepção interna, ou, em outros termos, às "apresentações" (Vorstellungen) e ao seu conteúdo descritivo dado, conforme a terminologia contemporânea, "em primeira pessoa". Segundo Smith (1988), é possível considerar a teoria de Christian von Ehrenfels, autor da época, como pertencendo à mesma orientação da "ontologia da mente" de Brentano, tendo-a como pressuposto e desempenhando, com relação a ela, o papel de uma "sofisticação ontológica" (Smith, 1988, p. 12). Esta genealogia nos esclarece a razão de Husserl (1931/1986) aproximar as duas formas de psicologia e opor-se igualmente a ambas.

É verdade que a teoria da Gestalt possui um grande significado para o desenvolvimento dos problemas psicológicos do século XIX e, sobretudo, do século XX. Partindo de uma concepção brentaniana de psicologia, tanto no método quanto na meta, esta teoria colocou em evidência o problema das aparições dotadas de articulação interna e, assim, contribuiu para a formação de um novo quadro teórico sobre os fenômenos psíquicos. Particularmente, a teoria dos "todos e das partes" (mereologia) e a ontologia subjacente às investigações psicológicas avançou grandemente com a contribuição dos psicólogos da teoria da Gestalt. Embora a constelação de influências intelectuais das pesquisas dos psicólogos da Escola de Berlim (Koffka, Köhler, Wertheimer) seja mais complexa do que esta fornecida aqui, cabe dizer que esta escola se origina deste fundo de pesquisas descritivas sobre a percepção e, particularmente, sobre a tese de que as apresentações perceptivas são internamente articuladas. Em comum, encontra-se a defesa de uma concepção não atomista da percepção, segundo a qual a sensação não pode ser concebida como uma "pura impressão qualitativa desprovida de forma e de relação" (Leclercq, 2012, p. 133), mas deve ser algo mais rico e mais complexo. Objetos como melodias não podem ser concebidos como "complexos de sensações" (um complexo de sons discretos sem articulação entre si), como na teoria clássica. No entanto, diferentemente dos autores da Escola de Graz e mesmo de Ehrenfels e de Husserl, os pesquisadores da Escola de Berlim concebem o fenômeno psíquico como possuindo uma organização autóctone, sem qualquer função superveniente, de natureza intelectual ou sensorial, que viria a articular os elementos anteriormente desprovidos de organização. A tese mais fundamental desta escola e de amplo significado metodológico não é senão a rejeição da hipótese de constância (Gurwitsch, 1936/2009c).

Se é possível esboçar-se uma compreensão geral da problemática da Gestalt de Ehrenfels à Escola de Berlim, deve-se começar pela consideração de que este quadro teórico geral se opõe tanto à tradição empirista da psicofisiologia (sobretudo, Helmholtz) quanto à tradição racionalista da psicologia intelectualista (sobretudo, de Kant e Herbart) segundo as 
quais a sensação somente poderia adquirir forma e relação de maneira exterior, por meio da associação ou da síntese com outras impressões, seja por meio de um mecanismo natural da consciência humana ou por meio da ação de faculdades superiores, puramente racionais. Por isto tudo, a análise descritiva da teoria da Gestalt, em especial aquela da Escola de Berlim, reivindica um "positivismo", de modo que se guia por aquilo que é imediatamente dado à experiência e dispensa construções teóricas e suas pressuposições especulativas (Leclercq, 2012). Estabelece-se, assim, de acordo com um empirismo mais radical do que aquele do associacionismo, porque, afinal, as formas e relações são dadas na própria experiência sensível e não, conforme o comenta Leclercq (2012), em uma "experiência segunda ‘impressões de reflexão’ - resultante do hábito associativo”' (p. 133). Todavia, a Psicologia da Gestalt jamais abandonou o ideal de concretização de uma psicologia natural.

Frente às problemáticas avançadas dentro do que se pode resumir como uma teoria da Gestalt, pode-se resumir a interpretação e a crítica que Husserl aplica a ela, especialmente em seu "Epílogo", em três pontos principais:

1 - Ela é um "sensualismo", posto que trata apenas de qualidades de sensação e de seus agrupamentos em complexos.

2 - A sua diferença para com outras formas de sensualismo, é que ela qualifica as qualidades de sensação como "todos que precedem as partes".

3 - Como outras formas de sensualismo, ela é incapaz de fornecer os princípios para a epistemologia sem redundar em uma confusão de registros.

Por outro lado, em uma forma alternativa de ver o problema, apesar de concordar com os princípios da fenomenologia transcendental e não buscar construir uma epistemologia apoiada sobre enunciados empíricos (como os positivistas), Gurwitsch não subscreve as teses de Husserl a respeito da teoria da Gestalt. Desde sua tese de doutoramento, de 1929, Gurwitsch (1929/2009a) buscou extrair o significado fenomenológico das teses psicológicas desta teoria e encontra solo fecundo para o desenvolvimento de uma descrição fenomenológica da percepção. Baseando-se nestes seus achados iniciais, o autor posiciona-se de maneira crítica frente ao "Epílogo" (Nachwort) de Husserl, publicado em 1931, publicando, no ano seguinte, o seu "Estudo crítico do Nachwort de Husserl" (Gurwitsch, 1932/2009b). As principais teses elaboradas pelo autor neste estudo podem ser resumidas e sistematizadas da seguinte forma: 
1 - A teoria da Gestalt pode ser interpretada fenomenologicamente, considerando-se, especialmente, as analogias entre o seu procedimento metodológico e aquele da própria investigação fenomenológica.

2 - Não diz respeito apenas a uma forma de conceber as qualidades de sensação, mas possibilita uma nova interpretação a respeito da organização da percepção, capaz de tornar ineficaz a oposição entre sensação (matéria) e percepção (interpretação).

3 - Permite uma reinterpretação da noção de "qualidades de sensação" e implica uma revisão da teoria da intencionalidade e de determinados aspectos das análises fenomenológicas da percepção, colocando um "novo" ponto de partida.

Estas duas posições serão analisadas em etapas. Primeiro, o esquema matéria-forma na teoria da percepção de Husserl, a fim de explicitar qual é o papel das qualidades de sensação em sua teoria e o que esta teoria oferece de novidade com relação ao sensualismo. Em um segundo momento, as aproximações entre fenomenologia e Psicologia da Gestalt, segundo a leitura de Gurwitsch, e as suas implicações para as análises fenomenológicas.

\section{O Esquema Matéria-Forma na Teoria da Percepção de Husserl}

A fenomenologia da percepção que Husserl desenvolve no período entre as $I L$ (Husserl, 1989) e "Ideias I" (Husserl, 1913/1976) baseia-se, fundamentalmente, sobre uma teoria da intencionalidade. Restringindo a complexidade da problemática envolvida na teoria da intencionalidade, um dos problemas que a teoria da intencionalidade de Husserl deve responder diz respeito à maneira como as multiplicidades sensíveis, vivenciadas, podem apontar para algo que é objetivo e que aparece como idêntico. A formulação clássica deste problema foi enunciada por Kant (1996) ao perguntar-se como é possível a unidade da experiência com base no fato de que é dada aos sentidos uma multiplicidade de sensações, ela mesma desprovida de organização. É preciso compreender que, no contexto da filosofia de Kant, os dados da sensibilidade vêm da intuição sensível, isto é, da faculdade pela qual o sujeito é afetado por objetos, de modo que são dados na mera passividade da consciência, como dados sensíveis puros, amorfos, desconectados entre si. A resolução de Kant consiste na tese de que, se o sujeito recebe pelos sentidos uma multiplicidade de sensações nãocombinadas, "caóticas", como o resultado da mera receptividade, então a combinação deve ser fornecida pelo entendimento, ou, mais particularmente, por uma síntese própria, que ele chamou de "unidade sintética do múltiplo" (Kant, 1996, p. 131). Com isso, o autor explicaria, 
em suma, o fato de que se tem uma experiência coerente e consistente do mundo, isto é, de que se tem "sentido". O problema sobre como a experiência sensível é organizada e, por isto, é dotada de sentido é caro à teoria da consciência de Husserl.

De acordo com a teoria de Husserl, a consciência apresenta dois conteúdos intrínsecos e genuínos, reais (reelle), isto é, conteúdos que entram na tessitura da consciência: as sensações e o próprio ato intencional (psíquico), matéria e forma. E ambos se diferenciam do que ele chamou, nas IL (Husserl, 1984), de "conteúdo intencional”. Em várias passagens das IL, Husserl (1984) afirma que os dados dos sentidos são desprovidos de sentido e que esta função de doar sentido cabe aos atos interpretativos. Em sua teoria da constituição, Husserl emprega um esquema que distingue duas funções: (a) a intencionalidade (ou "forma" intencional) e (b) o conteúdo sensorial (ou "matéria" sensível). Neste esquema, a matéria sozinha seria desprovida de sentido e de referência; para ser significativa, necessitaria de uma "interpretação objetivante" (objektivierende Deutung) (Husserl, 1984, p. 75) ou uma “apreensão" (Auffassung). Cabe à "interpretação" operar a doação de sentido, pela qual algo é efetivamente percebido, pela qual o que é dado é efetivamente um objeto. Em "Ideias I" (Husserl, 1913/1976), a distinção entre matéria e forma é reafirmada em uma nova

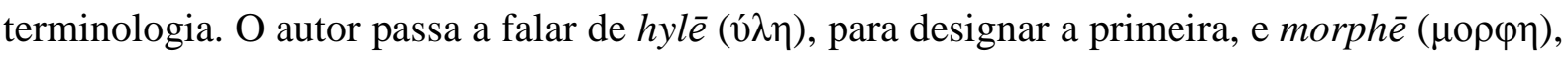
para a segunda. Com esta distinção, poder-se-ia corrigir uma insuficiência da teoria da intencionalidade de Brentano (1874/1995). Segundo Husserl (1913/1976, § 85), embora o mestre vienense tenha introduzido a importante distinção entre "fenômenos psíquicos" e "fenômenos físicos" na psicologia descritiva, demonstrando que apenas os primeiros teriam a propriedade da "intencionalidade", ele, no entanto, não chegou a conceber claramente o conceito de "momento material" do ato e, assim, não fez jus à referida separação como uma distinção entre, respectivamente, "momentos objetivos" (como cor, forma da coisa, etc.) e “momentos materiais" (dados de sensação).

Para Husserl (1913/1976), os momentos materiais, ou hiléticos, da vivência designam um conteúdo sensual não-intencional, vivências sensuais (sensuelle) que fazem parte dos “conteúdos de sensação”. Inclui-se, aqui, uma vasta gama de sensações, como, por exemplo, as sensações do campo dos cinco sentidos (táteis, visuais, sonoras, etc.), as sensações de sentimento, como as cócegas, a dor, o prazer, etc., e, também, os momentos sensuais da esfera das "pulsões", dos "instintos", etc. "Os dados hiléticos", esclarece Marcelle (2011, p. 64), "preenchem intuitivamente a nossa experiência com sensações atuais de um determinado objeto no interior de um determinado campo de sensação". Este conteúdo sensual (hylē) da vivência desempenha o papel de "matéria-prima", de "estofo material", sobre a qual as 
vivências propriamente intencionais são formadas. Husserl fala destes conteúdos sensuais, também, como "pedras de construção dos atos", mas que não devem ser confundidas com os próprios atos (Husserl, 1984). Eles são, por isso, "conteúdos primários" com relação a outros momentos das vivências. Eles correspondem ao "múltiplo sensível", caótico, da filosofia kantiana. Como tais, eles estão em um fluxo constante de mudanças e implicam a multiplicidade do que é sensivelmente intuído (por exemplo, a variedade potencialmente infinita de tons que compõem um objeto percebido).

Por outro lado, a "forma" (morphē) designa a "função animadora", também chamada, por Husserl (1913/1976; 1984), de "interpretação", de "apercepção" ou de "apreensão". A função animadora "dota" a multiplicidade dos dados dos sentidos, amorfa e inerte, de sentido, "anima-a", "enforma-a" (formt), integrando-o ao ato intencional propriamente dito. À multiplicidade recebida pelos sentidos e que entra na composição imanente da consciência a função animadora acrescenta o sentido de ser intencional, de apontar para algo como objetivo e, enquanto tal, como idêntico. A função animadora representa uma camada de vivências que "anima" (beseelende) os momentos sensuais, que lhes servem de matéria e que fundam os atos intencionais propriamente ditos. Esta animação indica uma "doação de sentido" (Sinngebung). Husserl (1913/1976) também chama esta função de "momento noético" (noetische Moment) da vivência, ou, simplesmente, de "noesis". Se os momentos sensuais não são, em princípio, intencionais (isto é, não são “consciência de algo"), então esta camada de doação de sentido, ao aplicar-se sobre eles, realiza-os, de fato, enquanto vivências intencionais. Esta atividade faz, então, daquilo que é dado enquanto "multiplicidade" nos "campos de sensação" (Sinnesfelder) uma unidade intencional, ou, o que dá no mesmo, algo "dotado de sentido", por oposição ao caos do múltiplo. Sem a função animadora, os dados dos sentidos seriam, portanto, desprovidos de referência objetiva, de significado. Assim, por exemplo, atesta-se a diferença entre um mero signo escrito, que é um mero material sensorial, e a palavra com significado, que pressupõe a intenção significadora.

As palavras hylē e morphē vêm do grego e significam, respectivamente, "matéria" e "forma". Consideradas de maneira pura, pode-se dizer que correspondem a "matérias sem forma e formas sem matéria" (formlose Stoffe und stofflose Formen) (Husserl, 1913/1976, p. 193). De um ponto de vista genético, a hylē não é, ainda, "vivência intencional". Por este motivo, Husserl prefere referir-se à função material por meio das expressões "dados hiléticos" (hyletische Data) ou "dados materiais" (stoffliche Data) (Husserl, 1913/1976, p. 194), em vez de "vivências sensíveis", ou semelhantes. Assim, a percepção ou intuição sensível não deve ser compreendida como correspondente aos dados hiléticos. Pelo contrário, ela deve ser 
entendida como uma "vivência de percepção" que inclui os dados hiléticos como seus componentes, porém já animados pela função significadora. Isso significa que a percepção é uma vivência intencional plena. Perceber não é perceber dados dos sentidos - a multiplicidade de tons e formas de um objeto e de seu entorno -, mas é perceber algo com significado. $\mathrm{O}$ objeto da percepção é a coisa "em carne e osso". Conforme esclarece Husserl (1984), a percepção é transcendente, refere-se a objetos, e contrapõe-se à sensação, que, como os atos, é apenas vivenciada. A percepção, de acordo com ele, "anima a sensação" (Husserl, 1984, p. 399) e torna possível a experiência de objetos (esta árvore, aquele som, este cheiro da flor etc.).

Os momentos hiléticos devem ser, por isso, claramente distinguidos dos "momentos de aparição das coisas", tais como, por exemplo, a coloração, a aspereza, o timbre etc. Quanto a estes últimos, Husserl (1913/1976, § 85) diz que eles se “exibem” (darstellen) de "maneira vivificada" (erlebnismäßig) por meio daqueles conteúdos. Isso significa que estes momentos de aparição das coisas, ou "perfis" (Abschattungen), incluem dados de sensação como seus conteúdos, mas pressupõem a atividade da função animadora, que os dota de sentido e, assim, os dirige à objetividade. Somente por meio desta função é que os dados dos sentidos podem entrar na "função de exibição" da percepção, que já se encontra vivificada pela "apreensão noética". É por meio desta função ou apreensão noética, animadora, que a consciência se realiza como sendo, de uma ponta a outra, consciência intencional, pois ela integra ao fluxo de consciência das vivências intencionais até mesmo aquelas vivências que, por princípio, carecem de intencionalidade, como é o caso dos conteúdos hiléticos. De acordo com a teoria de Husserl, é através da apreensão animadora que uma sensação sonora, como, por exemplo, o som produzido por um piano de calda, é por mim percebido como "nota de um piano" e, assim, tomado como um fenômeno verdadeiro, que faz parte de uma "sonata" e, assim, desperta em mim determinados sentimentos e é por mim valorada de tal e tal forma.

É fundamental compreender que a teoria fenomenológica da hylē e da morphē se distingue radicalmente de toda teoria fisicalista das sensações e de todo sensualismo. Para a teoria fisicalista das sensações, todas as sensações e aparições são o resultado de causas exteriores e que se escondem por trás das próprias aparições. As sensações são causadas por estímulos do mundo transcendente, dos quais nós nada sabemos, porque se ocultam por trás das sensações (Marcelle, 2011). A redução fenomenológica inibe qualquer posição a respeito do mundo transcendente - e, assim, a tomada, prima facie, da validade de uma teoria baseada nos estímulos, nas estruturas orgânicas, etc. E, mais, a teoria da percepção conduzida na esfera imanente demonstra que o ato de percepção não apresenta algo para o qual a sensação 
seria um signo, mas dá a coisa "em carne e osso". Para Husserl (1913/1976), com efeito, a teoria fisicalista da percepção falha em dois pontos cruciais. Primeiro, ela falha em lidar de modo rigoroso com o sentido do dado "coisa" e da "coisa em geral", falha em realizar uma fenomenologia da percepção genuína. Segundo, ela recai no absurdo de requerer, sempre novamente, a possibilidade de uma consciência capaz de visualizar a "causa oculta" das sensações, que se esconde por trás delas. Isto porque, se esta causa existe, ela deve ser, por princípio, perceptível e experimentável por alguma consciência possível, que possa ver mais longe; e, além disso, a percepção é vista como "representação", isto é, como uma indicação de um fenômeno sempre a outro, o qual substitui, o que recai em um círculo vicioso.

A concepção fenomenológica de consciência distancia-se, também, da concepção empirista e sensualista da consciência. O sensualismo consiste na tese de que o psiquismo está subordinado e restrito à irracionalidade da "matéria sem sentido" (a hylē). De acordo com esta concepção, a consciência é, de fato, de uma ponta a outra, uma "matéria sem sentido". Isto é válido, segundo Husserl (1913/1976), para concepções de consciência baseadas em teses como a dos "complexos psíquicos" (psychische Komplex), a da "fusão de conteúdos" (zusammengenschmolzene "Inhalte”) e a dos "feixes" ("Bündel”) ou "fluxos" de "sensações" (Ströme von “Empfindungen”). Se a consciência tem por base a matéria desprovida de sentido, sem apontar para algo que seja objetivo e que, como tal, possa ser identificado como o mesmo através do tempo ou por meio de atos distintos, então a consciência é incapaz de proporcionar qualquer sentido: nenhum sentido pode surgir em (ou de) "uma mistura qualquer" (in beliebigem Gemenge) diz Husserl (1913/1976, p. 196). Ora, se como o vimos, os dados sensuais não apontam nenhum "sentido", nenhum objeto correspondente, então uma concepção de consciência baseada neles é a de um total "non-sense". Uma função animadora, que atribua aos dados dos sentidos uma direcionalidade, é necessária na teoria de Husserl.

Do ponto de vista fenomenológico husserliano, o estudo das sensações só é adequado se está integrado ao estudo da vivência intencional e de seu papel constitutivo, isto é, somente na medida em que elas são capazes de "proporcionar possíveis tramas [Einschläge] no tecido intencional, possíveis matérias para formações intencionais" (Husserl, 1913/1976, p. 197). Uma "hilética pura", por exemplo, só recebe o seu significado pleno quando integrada ao vasto domínio de investigações da fenomenologia transcendental. Deste ponto de vista, passa a importar, sobretudo, de que modo as "unidades de sentido" constituídas pelas funções noéticas e hiléticas, enquanto compreendem uma multiplicidade de contínuos de consciência e de relações entre vivências, vinculam-se a algo unitário, homogêneo, a uma "consciência unitária abrangente de um só e mesmo algo objetivo" (Husserl, 1913/1976, p. 197). De tal 
modo, a hilética requer um complemento. A problemática fundamental que leva a esta exigência é a pergunta sobre como algo diferente da consciência chega a ela como "idêntico" (Selbiges) e, ainda mais, como uma unidade idêntica que é "visada" (vermeint) a partir da imanência da consciência. A resposta de Husserl (1913/1976) está em suas análises noéticonoemáticas.

\section{Uma Interpretação Fenomenológica da Teoria da Gestalt}

A interpretação que Gurwitsch dá à Psicologia da Gestalt é, contudo, diferente daquela de Husserl e não se opõe a uma teoria fenomenológica da consciência. Todavia, necessita que alguns de seus princípios sejam revisados. $\mathrm{O}$ autor interpreta esta teoria com base nas seguintes teses:

1 - A teoria da Gestalt possui um componente descritivo e um método de acesso a este componente descritivo que é análogo à redução fenomenológica.

2 - O componente descritivo da teoria da Gestalt pode ser interpretado como fenomenológico, ainda que não em nível transcendental, e possui importantes implicações para as investigações fenomenológicas e epistemológicas.

No texto "Fenomenologia da temática e do eu puro", de 1929, Gurwitsch explicita (1929/2009a) que o seu diálogo se estabelece com "Ideias I". O autor esclarece que os problemas constitutivos não são o seu assunto de pesquisa, mas tão-somente o seu horizonte. O ensaio de Gurwitsch não se localiza, propriamente, no registro da filosofia transcendental, embora seja orientado para ela. O autor pressupõe a redução fenomenológica, mas sem discuti-la. O que lhe interessa é justamente "o que jaz entre a fundação indiscutida da redução fenomenológica e os problemas que pertencem à fenomenologia transcendental: a esfera da consciência pura" (Gurwitsch, 1929/2009a, p. 194). Em particular, trata-se de um desenvolvimento da teoria da intencionalidade desenvolvida por Husserl em "Ideias $I$ " à luz da Psicologia da Gestalt. Por este motivo, trata-se de um avanço e de uma modificação desta teoria, em sua leitura.

Elaborando as suas análises fenomenológicas a partir da Psicologia da Gestalt, Gurwitsch (1929/2009a; 1955/2009d) demarca a diferença entre uma abordagem naturalística da consciência e uma abordagem puramente descritiva. A abordagem psicológica da consciência favorecida pela psicologia clássica pode ser definida como uma concepção 
"naturalística" da consciência (Gurwitsch, 1955/2009d). É a esta concepção que se refere Gurwitsch na afirmação de seu estudo de 1929: “A psicologia tradicional concebeu o sujeito psicológico como alocado em um mundo de estímulos objetivos" (Gurwitsch, 1929/2009a, p. 213). No interior deste quadro interpretativo, surge a problemática particular a respeito da relação entre os estímulos e o resultado de sua ação, a saber, os processos fisiológicos e as experiências sensoriais concomitantes. Segundo Gurwitsch (1955/2009d), a primeira tentativa de estabelecer esta relação na história da psicologia moderna é a hipótese de constância (doravante, HC). Ao lado da concepção de mundo físico, a HC foi aceita pelos psicólogos, sobretudo nos séculos XIX e XX, como um fundamento evidente por si mesmo e, dessa forma, ela guiou grande parte das pesquisas experimentais em psicologia e em psicofísica. Esta "hipótese" consiste na tese de que os dados sensoriais são "coordenados, elemento a elemento, de maneira estritamente unívoca, aos estímulos objetivos correspondentes" (Gurwitsch, 1929/2009a, p. 213). Particularmente, o que conta é a determinação exclusiva da estimulação local: "Sempre que a mesma área bem circunscrita de um órgão sensorial (p.ex., a retina) é estimulada pelo mesmo processo físico externo", afirma o autor, "o mesmo dado sensorial não falha em aparecer" (Gurwitsch, 1955/2009d, p. 113). A tese da constância perceptiva define-se pela correlação unívoca entre a estimulação e os dados sensoriais: "A mudança contínua na estimulação local é acompanhada pela mudança contínua nas sensações correspondentes" (Gurwitsch, 1955/2009d, p. 133). A constância perceptiva representa, em suma, esta variação concomitante e proporcional entre estímulos e sensações.

Todavia, nem sempre é possível observar essa constância unívoca entre a estimulação e aquilo que é percebido. Os fenômenos de ilusão perceptiva (a figura de E. Rubin, por exemplo) constituem um contraexemplo à HC. Nestes casos, o que se observa experimentalmente é que os estímulos permanecem constantes, mas que os dados sensoriais emergentes se modificam de uma forma ou de outra. Certamente, caso se conceba que os dados dos sentidos dependem e são causados inteiramente por estímulos físicos, não há estímulos discretos e bem determinados que possam corresponder à percepção de melodias, à relação de diferença, às percepções figurais, a determinados agrupamentos etc. Tudo isto "constitui um enriquecimento da percepção que não possui estímulo adicional que corresponda a ela" (Gurwitsch, 1936/2009c, p. 10). V. Benussi (citado por Gurwitsch 1936/2009c), da Escola de Graz, por exemplo, o interpretou como um fato que falaria a favor de sua teoria, pois, se não pode haver correspondência unívoca entre a sensação e a estimulação, então aquilo que é percebido deve ter sido produzido por um fator de ordem diferente da mera sensibilidade, ou seja, um fator de ordem intelectual (Gurwitsch, 
1964/2010, p. 88). Porém, o desenvolvimento das pesquisas em Psicologia da Gestalt conduziu a uma interpretação diferente do fenômeno perceptivo. Esta nova concepção não admite nem a distinção entre percepção e sensação, tampouco a distinção entre um objeto fundante e um objeto fundado (a não ser como "partes" e "todo" de uma mesma figura). Do ponto de vista desta teoria, as "qualidades de forma" só podem designar a "Gestalt com sua própria estrutura intrínseca" (Gurwitsch, 1936/2009c, p. 28). O conceito de "Gestalt" é o conceito descritivo fundamental desta nova concepção, pois permite um remanejamento das contradições e dos problemas da teoria clássica.

A derrogação da HC é base da inversão operada pela Psicologia da Gestalt e, para Gurwitsch (1929/2009a), possui uma estrutura básica comum com a redução fenomenológica, ainda que não alcance a sua radicalidade e universalidade. É este procedimento que, segundo o autor, abre uma "via" da Psicologia da Gestalt à fenomenologia transcendental. Neste sentido, é possível falar-se de uma "via pela Psicologia da Gestalt" como um contraponto ou mesmo um complemento à via que foi elaborada por Husserl em "Ideias I" (Husserl, 1913/1976). Nas palavras de Gurwitsch: “... a derrogação da hipótese de constância abre uma via possível de abordagem à concepção fenomenológica da consciência, uma concepção que ... é radicalmente oposta à concepção psicológica" (Gurwitsch, 1955/2009d, p. 115). A oposição entre a concepção fenomenológica e a psicológica, aqui, restringe-se a uma determinada concepção de psicologia (a saber, a naturalística) ou, ainda, a um determinado "momento" da pesquisa psicológica.

Com base neste princípio metodológico, a investigação psicológica fica restrita, em termos metodológicos e epistemológicos, ao dado psicológico no registro da descrição pura, isto é, àquilo que é dado tal como é dado no ato de consciência que está sob investigação (Gurwitsch, 1929/2009a, p. 213). Aquilo que deve ser tomado como "dado" não pode mais se referir às estimulações nem mesmo a qualquer realidade extrassensorial. O "dado" deve consistir naquilo que "aparece" em determinada percepção, isto é, o "percepto", tal como ele aparece. Trata-se de tomar o fenômeno por seu valor imediato (at face value) (Gurwitsch, 1955/2009d, p. 116), quer dizer, através do ato de consciência pelo qual ele se apresenta e apenas através deste mesmo ato. Após a rejeição da hipótese de constância, o fenômeno psicológico corresponde ao "noema perceptual” (Gurwitsch, 1955/2009d, p. 116). É este o objeto que, pela descrição e pela análise, deve ter os seus componentes e constituintes distinguidos e discriminados uns dos outros (Gurwitsch, 1955/2009d, p. 115). Isto significa que estes componentes e constituintes não são explicados ou classificados a partir de sua 
origem, como na teoria genética dos fenômenos figurais. Antes, eles devem ser descritos e analisados em um mesmo registro.

Por meio de seu princípio descritivo, por fim, a abordagem da Psicologia da Gestalt e a abordagem fenomenológica da consciência demonstram coincidir quanto a seu registro de investigação: a descrição pura daquilo que é dado tal como é dado. Este princípio possui, então, consequências importantes não apenas para a investigação psicológica da esfera perceptiva, mas, generalizando-o adequadamente, demonstra possuir um significado epistemológico mais profundo. É por esta via que os conceitos e as teses da Psicologia da Gestalt demonstram possuir significado e validade para a pesquisa fenomenológica e, ainda mais, para a própria fenomenologia transcendental, embora não alcance, a não ser por meio de determinados avanços metodológicos, o terreno transcendental de pesquisa.

Contudo, a partir deste ponto desenvolve-se toda uma revisão da teoria da intencionalidade, posto que, além do mais, a rejeição da HC envolve uma reformulação da teoria da percepção que a embasa, sobretudo de seu dualismo subjacente. Por conseguinte, a estrutura interna do objeto perceptivo não é mais concebida como heterogênea, composta por um setor de multiplicidade caótica e um setor responsável pela organização. Ela passa a corresponder a uma "unidade homogênea, ... internamente articulada e estruturada" (Gurwitsch, 1955/2009d, p. 116). Como mencionamos a respeito da teoria de Benussi, a hipótese de constância acarreta um dualismo entre as sensações puras e o ato perceptivo (de natureza intelectual). Segundo tal teoria, o processo perceptivo consistiria em, por um lado, puras sensações como multiplicidades desconexas e amorfas e, por outro lado, em funções psicológicas intervenientes que dariam a elas uma ordem (estrutura, organização, articulação, relação etc.). Por conseguinte, o próprio percepto deveria ser composto por dois estratos de níveis distintos, um dos quais é constante e deve estar em correspondência estrita com os estímulos e o outro é um fator superveniente que confere ao estofo sensível uma ordem.

A teoria da Gestalt, porém, recoloca a questão da "matéria", supostamente amorfa e caótica, que seria ordenada e articulada por uma função superveniente, a "forma" ou “apreensão". A inversão provocada pelos princípios da Gestalt leva a concluir que os "dados sensoriais" elementares não são senão entidades lógicas produzidas por um determinado tipo de comportamento e que o seu estatuto fenomenológico deve repousar sobre a noção de Gestalt, a partir da qual surge, e não o contrário. Considerando esta reformulação gestáltica da matéria, Gurwitsch (1929/2009a) retoma o problema kantiano da "unidade do múltiplo", citado acima, para afirmar que os problemas transcendentais também se colocam perante a Psicologia da Gestalt, porém de forma modificada. Porque, se Kant partia da doutrina de 
Hume sobre o "material sensorial caótico" (Gurwitsch, 1929/2009a, p. 215), a Psicologia da Gestalt deve partir, pelo contrário, "da ordenança, da estruturação e da organização originais do imediatamente dado, o material fenomenológico primitivo" (Gurwitsch, 1929/2009a, p. 215). Dito de outra forma, a Psicologia da Gestalt modifica o aspecto objetivo da dedução transcendental de Kant (1996) sobre a unidade do objeto da intuição sensível. A multiplicidade sensível passa a ser interpretada como um material dotado de articulação interna, isto é, como a própria Gestalt. Substitui-se, assim, a aplicação de conceitos pelo entendimento sobre o material sensível pela noção de "nexo gestáltico" (Gestaltverbindung) (Gurwitsch, 1929/2009a). E é com base neste ponto que Gurwitsch (1929/2009a) propõe uma revisão da fenomenologia da percepção, por ser, em sua visão, debitária da teoria clássica da percepção e pode ser reformulada com base nos princípios gestálticos.

Em primeiro lugar, Gurwitsch entende que a teoria clássica da percepção se baseia em uma concepção equivocada do que consiste o "tema", isto é, o objeto da consciência temática. De acordo com esta teoria, o objetivo perceptivo (chamado pelo autor de "tema") consistiria em um "agregado" de elementos, o qual seria, ademais, constituído em dois níveis. No entendimento do autor, isto inclui a distinção feita por Husserl entre hylē e morphē, isto é, entre um nível inferior de consciência correspondente às sensações e outros fatos elementares, e um nível superior, de atos de interpretação e doação de sentido, que se superpõem aos dados sensíveis. O conceito de "Gestalt" substitui o conceito de sensação, que amparava a concepção atomística e sensualista da consciência. A própria noção de sensação enquanto estofo elementar da percepção implica uma extrapolação do domínio daquilo que é imediatamente experimentado. De acordo com a concepção gestáltica, o tema deve ser concebido como um todo internamente articulado e estruturado e, portanto, significativo. Além disso, ele deve ser concebido como habitando um ambiente de outros objetos atuais e possíveis, um "campo" ou "contexto", com o qual se relaciona em termos de "figura e fundo".

Em segundo lugar, partindo-se do princípio de que toda apresentação perceptiva possui uma estrutura intrínseca, autóctone, o problema passa a ser, então, o da constituição de perceptos "destacados" dos contextos de significação primários nos quais se apresentam de maneira imediata. O próprio conceito de sensação só pode indicar o produto de um isolamento abstrativo. A partir deste ponto de vista, a interrogação sobre as variações que ocorrem no percepto deve resolver-se no interior do campo de sua própria estrutura intrínseca, sem fazer-se qualquer recurso a outras instâncias, sobretudo as de ordem superior. O problema central deixa de ser a questão sobre como a "qualidade de Gestalt" se produziria a partir dos dados elementares dos sentidos. Tal problema é desenvolvido no que o autor chama 
de "modificações temáticas" (Gurwitsch, 1929/2009a). A questão sobre a abstração de uma "parte" do percepto se torna um problema propriamente fenomenológico e um meio de resolver ou de propor uma nova compreensão sobre os problemas constitutivos da fenomenologia transcendental. É o que afirma, explicitamente, o autor: "Nossa questão diz respeito à estrutura do sentido noemático correlativo a este ato de abstração.” (Gurwitsch, 1929/2009a, p. 208).

Em terceiro lugar, estas últimas questões levam a interrogar a natureza específica da função da atenção, que está diretamente envolvida no destacamento temático de uma "parte" do todo internamente estruturado. Trata-se de uma função unitária ou de uma função heterogênea? Esta é uma questão auxiliar e que está, também, implicada nos problemas constitutivos da fenomenologia (Husserl, 1913/1976). A teoria psicológica clássica sobre a atenção a considerou como uma função unitária, homogênea, e sempre idêntica em suas realizações, responsável por centrar a consciência sobre um tema, realçar um objeto ou um aspecto do objeto, destacando-o de seu contexto, etc. A função da atenção seria a mesma para todos os objetos aos quais ela se dirige, iluminando-os ou dirigindo o foco de luminosidade para outros objetos. Nisto consiste o que o autor chamou, de maneira crítica, de "teoria do holofote" (Gurwitsch, 1929/2009a, p. 241), que, contudo, é, também, assumida por Husserl (1913/1976). A teoria desenvolvida por Gurwitsch (1929/2009a) demonstra, pelo contrário, que "atenção" é um nome para funções bastante diferentes entre si e que ela exige uma concepção contextual da consciência. Nas palavras de Gurwitsch (1929/2009a), “a consciência não é um olhar fixo para algo e que o tema não é, por assim dizer, um ponto isolado" (Gurwitsch, 1929/2009a, p. 223). Em outros termos, a sua teoria do campo de consciência permite avançar a análise da intencionalidade a partir de um novo ponto de partida que considere o fenômeno de contexto ou de Gestalt. E tudo isto se desenvolve na esteira de modificações teóricas oriundas de uma leitura gestáltica dos problemas fenomenológicos básicos.

\section{Considerações Finais}

Com a interpretação que Gurwitsch dá à teoria da Gestalt, pode-se concluir, em primeiro lugar, que esta teoria remove o dualismo sensação-percepção e o papel de uma função intelectiva doadora de sentido, posto que a própria experiência perceptiva exibe, de imediato, a significação, ou seja, coerência e organização. Com isto, a reprovação husserliana quanto ao fato de que a teoria da Gestalt corresponderia somente a uma reinterpretação dos 
"dados dos sentidos", substituindo a descrição de átomos por uma descrição de todos, seria falsa, pois se trata não apenas de descrever em nova linguagem a hyle, mas de reinterpretar o seu papel e, também, o da morphē, da função animadora. Com efeito, conduz a uma nova interpretação integral da teoria intencionalidade e da teoria da percepção em linhas fenomenológicas (Gurwitsch, 1929/2009a; 1964/2010). Em segundo lugar, é possível concluir que esta teoria ocupa uma posição intermediária entre a psicologia empírica e a fenomenologia transcendental e que, por sua dedicação à descrição da experiência imediata, pode ser concebida como uma via alternativa à redução, tal como a via psicológica preconizada por Husserl (2001). Sendo assim, e com toda a cautela de uma metodologia fenomenológica, ela não incorreria, necessariamente, nos erros epistemológicos e metodológicos do psicologismo denunciados por Husserl (1913/1976; 1984; 1931/1986), desde que, contudo, siga-se a própria delimitação proporcionada pela interpretação de Gurwitsch (1929/2009a; 1964/2010), que deixa de lado, por exemplo, o isomorfismo. Desta perspectiva, a reprovação de Husserl (1931/1986) sobre o papel epistemológico da teoria da Gestalt estaria equivocada, pois ela é capaz de sustentar uma fenomenologia eidética e transcendental. A delimitação de Gurwitsch, todavia, conduz à pergunta de se a teoria da Gestalt defendida por ele corresponde, ao final, de fato àquela defendida pelos autores da Escola de Berlim.

Este conjunto de questões abre um novo horizonte de pesquisas quanto às conexões entre fenomenologia e psicologia, no geral, mas, também, sobre a própria precisão da interpretação de Gurwitsch, sobretudo tendo-se em conta os desenvolvimentos posteriores das análises de Husserl. Em especial, deve dar-se destaque às elaborações sobre o tempo interno da consciência e sobre a síntese passiva. Que estatuto podem ter as Gestalten à luz destas investigações? E o que dizer da hylē na obra tardia de Husserl? Ainda, será possível que, mesmo estando correta esta interpretação de Gurwitsch, a sua teoria do campo da consciência recebe novo contorno se considerada sob o prisma da fenomenologia genética? Novas pesquisas interpretativas e interdisciplinares devem ser realizadas a partir destas questões.

\section{Referências}

Brentano, F. (1995). Psychology from an Empirical Standpoint (A. C. Rancurello, D. B. Terrell, \& L. L. McAlister, Trads.). New York: Routledge. (Obra original publicada em 1874) 
Gurwitsch, A. (2009a). Phenomenology of Thematics and of the Pure Ego: Studies of the Relation Between Gestalt Theory and Phenomenology. In F. Kersten (Ed.), The Collected Works of Aron Gurwitsch (1901-1973): Studies in Phenomenology and Psychology (Vol. 2, pp. 193-317). Dordrecht: Springer. (Obra original publicada em 1929)

Gurwitsch, A. (2009b). Critical Study of Husserl's Nachwort. In F. Kersten (Ed.), The Collected Works of Aron Gurwitsch (1901-1973): Studies in Phenomenology and Psychology (Vol. 2, pp. 119-127). Dordrecht: Springer. (Obra original publicada em 1932)

Gurwitsch, A. (2009c). Some Aspects and Developments of Gestalt Psychology. In F. Kersten (Ed.), The The Collected Works of Aron Gurwitsch (1901-1973): Studies in Phenomenology and Psychology (Vol. 2, pp. 1-61). Dordrecht: Springer. (Obra original publicada em 1936)

Gurwitsch, A. (2009d). The Phenomenological and the Psychological Approach to Consciousness. In F. Kersten (Ed.), The Collected Works of Aron Gurwitsch (19011973): Studies in Phenomenology and Psychology (Vol. 2, pp. 99-118). Dordrecht: Springer. (Obra original publicada em 1955)

Gurwitsch, A. (2010). The Field of Consciousness. In L. Embree, L., \& R. Zaner (Eds.), The Collected Works of Aron Gurwitsch (1901-1973): The Field of Consciousness: Theme, Thematic Field, and Margin (Vol. 3, pp. 1-412). Dordrecht: Springer (Obra original publicada em 1964)

Husserl, E. (1976). Ideen zur einer reinen Phänomenologie und phänomenologischen Philosophie, Ersters Büch: Allgemeine Einführung in die Phänomenologie: Husserliana $(G W)$, Bd. III/1 (Hrsg. Karl Schumann). Den Haag: Martinus Nijhoff. (Obra original publicada em 1913)

Husserl, E. (1984). Logische Untersuchungen, Zweiter Band, Erster Teil: Untersuchungen zur Phänomenologie und Theorie der Erkenntnis: Husserliana, Bd. XIX-1. Dordrecht: Springer.

Husserl, E. (1986). Nachwort. In E. Husserl, Ideen zu einer reinen Phänomenologie und phänomenologischen Philosophie: Drittes Buch: Die Phänomenologie und die Fundamente der Wissenschaften. Husserliana, Bd. V. Hamburg: Meiner. (Obra original publicada em 1931)

Husserl, E. (2001). Psychologie phénoménologique (1925-1928) (P. Cabestan, N. Depraz, \& A. Mazzú, Trads.). Paris: J. Vrin. 
Husserl, E. (2012). A crise das ciências europeias e a fenomenologia transcendental: Uma introdução à filosofia fenomenológica (D. F. Ferrer, Trad.). Rio de Janeiro: Forense Universitária.

Kant, I. (1996). Critique of Pure Reason: Unified Edition (W. S. Pluhar, Transl.). Cambridge: Hackett Publishing.

Leclercq, B. (2012). Lois régissantes phénomènes: Légalités noématiques, noétiques et hylétiques. Bulletin d'analyse phénoménologique, 8(1), 121-139. Recuperado de http://popups.ulg.ac.be/1782-2041/index.php?id=524

Marcelle, D. (2011). The Phenomenological Problem of Sense Data in Perception: Aron Gurwitsch and Edmund Husserl on the Doctrine of Hyletic Data. Investigationes Fenomenológicas, (8), 61-76. Recuperado de https://www2.uned.es/dpto_fim/InvFen/InvFen08/pdf/04_MARCELLE.pdf

Peres, S. P. (2015). A fenomenologia de Husserl no contexto da psicologia na virada para o século XX. Estudos e Pesquisas em Psicologia, 15(3), 986-1005. Recuperado de http://pepsic.bvsalud.org/scielo.php?script=sci_arttext\&pid=S1808$42812015000300012 \& \operatorname{lng}=\mathrm{pt} \& \operatorname{tlng}=\mathrm{pt}$

Ramstead, M. J. D. (2015). Naturalizing what? Varieties of naturalism and transcendental phenomenology. Phenomenology and the Cognitive Sciences, 14(4), 929-971. doi:10.1007/s11097-014-9385-8

Smith, B. (1988). Gestalt Theory: An essay in philosophy. In B. Smith (Ed.), Foundations of Gestalt Theory (pp. 11-81). Munich, Vienna: Philosophia Verlag.

\section{Endereço para correspondência}

\section{Hernani Pereira dos Santos}

Rua Senador Souza Naves, 289 sala 33, Centro, Londrina - PR, Brasil. CEP 86010-160

Endereço eletrônico: hernani.santos@pucpr.br

Recebido em: 05/07/2020

Aceito em: 07/09/2020

\footnotetext{
Notas

* Psicólogo, graduado pela Universidade Estadual de Londrina, doutorando pela UNESP/Assis. Professor assistente na PUCPR/Londrina.
}

Este artigo de revista Estudos e Pesquisas em Psicologia é licenciado sob uma Licença Creative Commons Atribuição-Não Comercial 3.0 Não Adaptada. 